\title{
Relationship between the frequency of touching and status in institutionalized profoundly retarded
}

\author{
WILLIAM V. RAGO, JR. and CHARLES C. CLELAND \\ University of Texas at Austin, Austin, Texas 78712
}

\begin{abstract}
Touching behavior in a group of institutionalized, profoundly mentally retarded adult males was analyzed with respect to the member's status within his group. Results indicated that the lower the member's status, the more frequently he would touch other group members. This suggested that touch functions as an appeasement gesture in this group of residents. Results were discussed as they related to touch and status in nonretarded individuals.
\end{abstract}

Research by Henley (1973) has explored the role of touch as a status variable. She found that individuals high in status can touch those low in status without reciprocation. She suggests that individuals who possess the privilege of touch are communicating power or status. The present research reports on the function of touch in the nonverbal communication of an institutionalized group of profoundly mentally retarded adult males. Status was determined by the frequency of initiated aggression within the group. The higher this frequency of a resident relative to the other residents, the higher the resident's status. Following Goffman's (1956) institutional observation concerning the positive relationship between the privilege of touch and status, it was hypothesized that high-status profoundly retarded residents would touch other residents more and would themselves be touched less frequently.

\section{METHOD}

\section{Subjects}

Fourteen institutionalized profoundly mentally retarded adult males served as subjects. All were members of the same group at least 8 months prior to the initial observations. All subjects were ambulatory and had functional vision and audition. Chronological ages and social quotients (Vineland Social Maturity Scale), respectively, were: mean $=39.85$ years, $\mathrm{SD}=4.41$ years; mean $=11.0, \mathrm{SD}=3.59$. The setting for all the observations was the dormitory playroom, which measured $6.40 \times 5.49 \mathrm{~m}$. The room was lined by $1.83-\mathrm{m}$ plastic benches; otherwise, it was empty. There was one attendant in charge of the group at all times.

\section{Procedure}

The data were collected over a 2-week period. While the group was in the playroom, they were observed by means of a time-sampling procedure adapted from Esser, Chamberlain, Chapple, and Kline (1970). The observers recorded subject interactions as they occurred. The observers identified the participants with regard to who initiated and who received the interaction. The interactions were classified as aggressive or touching interactions. Examples of aggressive interactions included hitting, pushing, taking, and kicking persons and/or objects. A complete index of the 31 aggressive behaviors can be found in Rago (1976). Touching interactions were operationally defined as interactions involving nonaggressive physical contact. This dichotomy sufficiently handled the observed interactions since the profoundly retarded are unsocialized and nonverbal.

The status or dominance hierarchy among the subjects was determined by ranking the most aggressive resident (most initiated aggression) as the highest in the status hierarchy, followed by the next most aggressive resident. In this way a linear hierarchy ranging from the most to the least aggressive resident was established.

\section{Observer Reliabilities}

Three observers were used throughout the study. Reliability coefficients calculated according to Ebel's (1951) intraclass correlation formula were: aggression, $\mathrm{r}=.83$, and touching, $r=.91$. Reliabilities were computed the last day of the first week.

\section{RESULTS}

A clear hierarchy was established for dominance structuring within the group. Of the 533 aggressive acts observed during the study, 261 were initiated in the first week. Rank ordered dominance hierarchies computed for each week separately had a correlation of $.88(\mathrm{p}<.01$, Spearman rank order correlation $)$. A rank order correlation between dominance hierarchy (both weeks combined) and a rank ordering of subjects from least to most frequently assaulted was .87 $(\mathrm{p}<.01)$. This finding lends additional credibility to the discovered dominance hierarchy by indicating that residents who frequently assaulted other residents were themselves rarely assaulted.

Of the 142 observed instances of touching, Week 2 had 14 more touching interactions than Week 1, a nonsignificant difference. A rank order correlation between dominance hierarchy and rank order of the residents from most touching interactions to fewest initiated was -.25 . Although the relationship was not significant, there was a tendency toward the more frequent use of touch in nonaggressive residents. For example, the five highest ranked aggressive residents, considered to be of high status within the group, 
initiated $491(92 \%)$ of the 533 aggressive acts. Yet, four of the five most frequent touchers initiated only 39 aggressive acts. There was only one subject who was both an aggressor and a toucher. Thus, a percentage analysis for the four most frequent aggressors and the four most frequent touchers (excluding data for the one subject who was high in both aggression and touching) showed that the four aggressive subjects initiated $65 \%$ of the aggression, but only $4.2 \%$ of the touches. However, the frequency with which they were touched accounted for $40 \%$ of the observed touching interactions. The four most frequent touchers who initiated $70 \%$ of the touching interactions were low in aggression initiated (7.3\%); yet, the number of times they were assaulted accounted for $50 \%$ of the group's aggression.

\section{DISCUSSION}

The hypothesis that higher status residents would touch lower status residents more frequently received little support. Rather, the data supports the opposite conclusion. The lower the resident's status within the group, the more likely he is to touch other residents. Thus, with the one exception, in this group of institutionalized profoundly retarded males, touch is more likely to communicate subordinate status rather than dominance. The dominant subjects were touched 56 times at the initiation of the four most frequent touchers, who were low-status residents. As such, the function of touch may be viewed as an appeasement geature in a manner analogous to Hutt and Onsted's (1966) description of gaze avoidance in autistic children. As an appeasement gesture, the more frequent use of touch in low-status residents is reminiscent of the grooming patterns established by other primates. Within the group, the dominant or alpha male is groomed by the lower status members. Eibl-Eibesfeldt (1975) interprets this form of nonaggressive contact as an appeasement gesture on the part of the lower status primates.
The reasons for the specificity of profoundly retarded behaviors as discovered in this study (the resident who is aggressive does not touch and the toucher does not assault) are at this point open to speculation. It might be suggested that this behavioral specificity is the product of an interaction between the length of time that these residents have been together, and therefore know what to expect of each other, and their very limited intelligence, which generates behavioral stereotypy. Regardless of the speculation on this point, it may be concluded that what is communicated by touch in this profoundly retarded group is at variance with what is communicated in nonretarded groups.

\section{REFERENCES}

EbeL, R. L. Estimation of the reliability of ratings. Psychometrika, 1951, 16, 407-424.

EibL-EibesfeldT, I. Ethology: The biology of behavior. New York: Holt, Rinehart, \& Winston, 1975.

Esser, A., Chamberlain, A., Chapple, E., \& Kline, N. Territoriality of patients on a research ward. In $\mathbf{H}$. Proshansky, W. Ittelson, \& L. Rivlin (Eds.), Environmental psychology: Man and his physical setting. New York: Holt, Rinehart, \& Winston, 1970.

Goffman, E. The nature of deference and demeanor. American Anthropologist, 1956, 58, 473-502.

Henley, N. M. Status and sex: Some touching observations. Bulletin of the Psychonomic Society, 1973, 2, 91-93.

HutT, C., \& Onsted, C. The biological significance of gaze aversion with particular reference to the syndrone of infantile autism. Behavioral Science, 1966, 11, 346-356.

RAGo, W. V. Territoriality in the profoundly mentally retarded. In C. C. Cleland, L. W. Talkington, \& J. D. Swartz (Eds.), Second annual conference on the profoundly retarded. San Antonio, Tex: March 1976.

(Received for publication January 10, 1978.) 